\title{
Documento: \\ X Encontro de Geógrafos da América Latina Por uma Geografia Latino-Americana. Do Labirinto da Solidão ao Espaço da Solidariedade
}

Mónica Arroyo*

\section{O Encontro de Geógrafos da América Latina}

O Encontro de Geógrafos da América Latina (EGAL), realizado a cada dois anos em diferentes países, tem por objetivo promover o debate e intercâmbio da produção geográfica contemporânea entre pesquisadores das diversas instituiçôes latino-americanas, constituindo um espaço privilegiado para a discussão do estado atual do conhecimento.

No processo de globalização contemporâneo, o intercâmbio de experiências acadêmicas adquire uma relevância ainda maior na geração de conhecimento, fato que se acentua num campo disciplinar que tradicionalmente busca explicar a diferenciação dos lugares terrestres e as relações entre os fenômenos na superfície da Terra. Hoje, como bem assinalou Milton Santos, cada lugar tem de ser analisado como uma funcionalização da totalidade, isto é, como uma parte do mundo. Nesse sentido, a própria noção de espaço se re-qualifica em face de novas dinâmicas sociais colocadas pelo movimento da atualidade, que redefine o papel da técnica inclusive na esfera do conhecimento e da ciência geográfica em particular.

Aproximar os geógrafos latino-americanos num período como o que vivenciamos é essencial, pois essa região do globo vive um momento crucial de sua história, submetida às determinaçôes novas da recente mundialização (extremamente excludente do ponto de vista social e espacial) e sem ter concluído algumas das tarefas básicas postas pela modernidade (entre elas, a da universalização da cidadania). Nesse momento de re-

Professora Doutora do Departamento de Geografia da Faculdade de Filosofia, Letras e Ciências Humanas FFLCH/USP.Email: mmarroyo@usp.br 
estruturação das funções da periferia é fundamental intercambiar estudos e reflexões em variadas escalas geográficas, de modo a fundamentar o campo disciplinar com instrumentos analíticos precisos, que são construídos necessariamente sobre uma sólida base comparativa. Assim, os temas clássicos da geografia (como a relação sociedade-natureza, a relação cidade-campo, as migraçôes e as fronteiras, entre outros) necessitam ser rediscutidos sob o signo do presente histórico. As afinidades e os interesses comuns dos países da América Latina qualificam o diálogo entre seus geógrafos como uma interlocução privilegiada no mundo globalizado.

\section{Breve histórico dos Encontros}

No ano de 1987, na cidade de Rio Claro, a partir das iniciativas de um grupo de geógrafos dirigidos pelo Professor Doutor Antonio Olívio Ceron, da UNESP (Universidade Estadual de São Paulo), foi organizado o Primeiro Encontro de Geógrafos de América Latina (I EGAL). As reuniōes realizaram-se na cidade de Águas de São Pedro e os participantes constituíram um número relativamente pequeno de estudiosos procedentes da Argentina (25 pessoas), Uruguai (1), Venezuela (1), México (1), Costa Rica (1) e do Brasil um número maior (109).

Após os regimes militares ditatoriais que dominaram este sub-continente, impondo o isolamento entre as pessoas em todos os países, surge a necessidade imperiosa de comunicação entre os cientistas de todas as áreas e dos geógrafos em particular. Perante essas mudanças era preciso discutir questôes teórico-metodológicas e novas formas de pesquisa. O I EGAL foi importante porque mostrou os interesses dos geógrafos de reunir-se para discutir os temas que preocupavam a academia. Os organizadores especificaram seus objetivos salientando que desejavam "o intercâmbio de experiências e conhecimentos científicos entre geógrafos da América Latina quanto à situação atual do conhecimento geográfico, formação do geógrafo e sua atuação como profissional”.

Nesse Encontro foi decidido que as reuniões se realizariam a cada dois anos em países latino-americanos alternados do Hemisfério Norte e do Sul. Outro critério estabelecido foi o de que não haveria uma única instituição responsável, mas a organização e o financiamento de cada evento corresponderiam às instituiçóes do país eleito. A escolha do país sede da próxima reunião seria decidida, no final de cada encontro, em assembléia plenária com representantes de todos os países presentes.

A partir desse momento, foram realizados, com a regularidade prevista, os seguintes encontros: 


\begin{tabular}{|l|c|l|l|}
\hline I EGAL & 1987 & Águas de São Pedro & Brasil \\
\hline II EGAL & 1989 & Montevidéu & Uruguai \\
\hline III EGAL & 1991 & Toluca & México \\
\hline IV EGAL & 1993 & Mérida & Venezuela \\
\hline V EGAL & 1995 & Havana & Cuba \\
\hline VI EGAL & 1997 & Buenos Aires & Argentina \\
\hline VII EGAL & 1999 & San Juan & Porto Rico \\
\hline VIII EGAL & 2001 & Santiago & Chile \\
\hline IX EGAL & 2003 & Mérida & México \\
\hline X EGAL & 2005 & São Paulo & Brasil \\
\hline
\end{tabular}

A sede do próximo encontro, em 2007, será a cidade de Bogotá, na Colômbia, conforme foi decidido na plenária final do X EGAL.

\section{OXEGAL}

Ao sediar o X Encontro de Geógrafos da América Latina, o Departamento de Geografia, da Faculdade de Filosofia, Letras e Ciências Humanas da Universidade de São Paulo, reafirmou seu compromisso com o intercâmbio acadêmico latino-americano, posto já como uma tradição da prática departamental. Para assumir a organização, o Departamento convidou três importantes instituiçōes brasileiras: o Programa de Pós-Graduação em Integração da América Latina da Universidade de São Paulo (PROLAM/USP), a Associação de Geógrafos Brasileiros (ABG), a Associação Nacional de Pós-Graduação e Pesquisa em Geografia (ANPEGE), que aceitaram o desafio de dar continuidade ao aprofundamento da reflexão sobre os problemas e as questôes que a contemporaneidade nos impõe. As dificuldades enfrentadas pelos países latino-americanos, no labirinto do presente, exigem repensar as possibilidades de um futuro fundado em uma nova solidariedade. Foi justamente este pensamento que deu origem ao título e ao espírito do $\mathrm{X}$ EGAL: "Por uma geografia latinoamericana. Do labirinto da solidão ao espaço da solidariedade", realizado entre os dias 20 e 25 de março de 2005, na Universidade de São Paulo. 
Tratou-se de um evento de grande porte, tanto em função do número de países envolvidos na programação como do número de participantes que circularam nos cinco dias do evento (aproxiadamente 2500 pessoas). Os números a seguir expressam, em parte, essa grandeza: 1503 resumos aprovados pela Comissão Científica; 2131 autores e co-autores responsáveis por esses resumos; 966 trabalhos completos recebidos, fazendo parte dos Anais editados em CD-Rom, de 16744 páginas.

Questôes de importância científica e política foram discutidas no evento, reunindo os principais nomes da geografia latino-americana, em 3 conferências, 25 mesas redondas, 51 comunicações coordenadas, 193 sessões de comunicações livres, 88 painéis e cinco vídeos.

Os conferencistas que prestigiaram o X EGAL foram os professores: Amalia Inés Geraiges de Lemos (Universidade de São Paulo - Brasil), a cargo da conferência de abertura intitulada "América Latina: a procura de uma Geografia mestiça"; Anibal Quijano (Universidad Mayor de San Marcos - Peru), cuja conferência se denominou "Don Quijote y los Molinos de Viento en América Latina"; e Carlos Augusto de Figueiredo Monteiro (Universidade de São Paulo - Brasil) responsável pela conferência de encerramento, intitulada "América Latina: da criação passada à invenção necessária". Exposiçōes brilhantes que aportaram um rico e amplo universo de indagaçôes, instrumento fundamental na compreensão de nossas realidades continentais contemporâneas.

Duas sessōes especiais, denominadas “Trajetórias Geográficas Latino-americanas”, foram o momento no qual os grandes mestres - professores Aziz Nacib Ab'Saber (USPBrasil), Elena Chiozza (Universidad Nacional de Luján-Argentina) e Angel Bassols Batalla (Universidad Autónoma de México) - expusseram as próprias experiências como docentes e pesquisadores ao longo de suas brilhantes carreiras.

As mesas redondas foram compostas por dois especialistas brasileiros, dois estrangeiros e um coordenador, representantes de diferentes instituiçôes públicas do continente. As temáticas abordadas bem demonstram as principais questōes na pauta de discusão da disciplina, entre elas, Para onde vai a América Latina?; Mobilidade e identidade nas dinâmicas territoriais; Território, finanças e informação na América Latina; Mundialização e metrópoles latino-americanas; Cidades médias e pequenas no processo de globalização; Presente e futuro dos camponeses e indígenas na América Latina; Novas tecnologias da informação e conhecimento do território; Mudanças ambientais globais: a América Latina no contexto; Estudos ambientais na Amazônia e politicas territoriais; Recursos hidricos e apropriação: a Bacia Platina e o Aqüifero Guarani em discussão. Os ricos debates animados pelas mesas redondas, assim como pelas sessões das outras modalidades que fizeram parte da programação, confirmam a importância destes foruns para fortalecer os laços científicos inter-regionais. 
Como possibilidade de um fértil diálogo, o X EGAL certamente colaborou para imaginar um espaço geográfico mais justo e soberano. Desejamos dar continuidade à consolidação de uma Geografia Latino-americana, em 2007, na cidade de Bogotá.

\section{COMISSÃ0 ORGANIZADORA}

Presidente

Amalia Inés Geraiges de Lemos (DG/USP)

Membros

Maria Cristina Cacciamali (PROLAM/USP)

José Borzachielo da Silva (ANPEGE)

Jorge Luís Borges Ferreira (AGB)

Ailton Luchiari (DG/USP)

Antônio Carlos Robert de Moraes (DG/USP)

Cleide Rodrigues (DG/USP)

Júlio César Suzuki (DG/USP)

Jurandyr Sanches Ross (DG/USP)

María Laura Silveira (DG/USP)

Mónica Arroyo (DG/USP)

Rita de Cássia Ariza da Cruz (DG/USP)

Roseli Pacheco (DG/USP)

Tarik Resende de Azevedo (DG/USP) 
A Revista Cadernos PROLAM/USP é uma publicação periódica semestral, indexada, com Conselho Editorial de Arbitragem. O eixo temático é a integração da América Latina analisando sob quaisquer das seguintes dimensões: social, econômica, política, cultural e relaçôes internacionais. Todo trabalho é submetido ao Conselho Editorial através de dupla arbitragem anônima. 


\section{Normas de publicação}

1. As colaborações enviadas à Revista Cadernos PROLAM/USP deverão ser escritas em português, inglês, espanhol ou francês;

2. Extensão dos textos: Todo artigo deve ter no máximo 60.000 caracteres;

3. Forma de apresentação: Todo trabalho deve ser encaminhado à Redação em disquete acompanhado de duas cópias impressas $\mathrm{O}$ autor deve indicar sua filiação acadêmica e seu endereço para correspondência, que será publicado visando eventuais contatos por parte de outros pesquisadores. Todo artigo deverá estar acompanhado por um resumo (em português e inglês) de aproximadamente 10 linhas e por 5 palavras-chave (em português, inglês ou espanhol).

4. Citaçôes: Devem aparecer no corpo do texto, entre parênteses, indicando sobrenome do autor, data da publicação, página(s) citada(s). Por exemplo (Brown 1990: 70-75). No caso de diferentes títulos do mesmo autor no mesmo ano, o dado diferencial será uma letra após a data. Por exemplo: (Brown 1990a: 104-107).

Estas citações abreviadas enviam à bibliografia no final do artigo e que deve apresentar indicaçōes completas, como segue:

Livro: SOBRENOME, Nome do Autor. Titulo do Livro. Edição. Local de publicação, Editora, ano de publicação, quantidade de páginas.

Artigo de revistas: SOBRENOME, Nome do Autor. "Título do Artigo". Título do Periódico, Número do Volume, Data do Volume, Páginas (inicial e final).

Artigo de coletâneas: SOBRENOME, Nome do Autor. "Título do Trabalho", in SOBRENOME, Nome do Organizador. Título da Coletânea. Local de Publicação, Editora, Data, Páginas (inicial e final).

5. Notas de Rodapé: podem ser utilizadas quando for preciso introduzir uma conceituação, uma discussão, uma digressão etc., que no corpo do texto quebraria a fluência do discurso.

6. Ilustraçôes: devem ser utilizadas quando importantes para o entendimento do texto, pedindo-se que fotos, mapas, gráficos ou tabelas tenham boa resolução visual, de forma a permitir uma reprodução de qualidade.

7. Exemplares do Autor: serão enviados a cada autor quatro exemplares do número em que estiver publicada sua colaboração. 
8. Restriçôes: todo material encaminhado à Revista Cadernos PROLAM/USP deve ser Inédito no Brasil e estar rigorosamente de acordo com as Normas de Publicação, caso contrário, não serão apreciados. Os dados e conceitos são de exclusiva responsabilidade do autor.

\section{Endereço PROLAM/USP}

Rua do Anfiteatro, 181 - Colméia - Favo 1

CEP 05508-900 - Cidade Universitária - SP

Fone/Fax: 3091-3587 - 3091-3589 - 3815-0167

E-mail: prolam@usp.br

Home-page: www.usp.br/prolam 